\title{
Smartphone use and academic performance: A literature review
}

\author{
Simon Amez ${ }^{\mathrm{a}, \mathrm{c}, *}$, Stijn Baert ${ }^{\mathrm{b}, \mathrm{c}}$ \\ ${ }^{a}$ Ghent University, Belgium \\ ${ }^{\mathrm{b}}$ Ghent University, Research Foundation - Flanders, University of Antwerp, Université catholique de Louvain, Institute for Labour Economics (IZA), \\ Global Labour Office (GLO), IMISCOE, Belgium \\ ${ }^{\mathrm{c}}$ Sint-Pietersplein 6, B-9000 Ghent, Belgium
}

\section{A R T I C L E I N F O}

\section{Keywords:}

Smartphone use

Smartphone addiction

Academic performance

Literature review

Causality

\begin{abstract}
A B S T R A C T
We present the first systematic review of the scientific literature on smartphone use and academic success. We synthesise the theoretical mechanisms, empirical approaches, and empirical findings described in the multidisciplinary literature to date. Our analysis of the literature reveals a predominance of empirical results supporting a negative association between students' frequency of smartphone use and their academic success. However, the strength of this association is heterogeneous by (a) the method of data gathering, (b) the measures of academic performance used in the analysis, and (c) the measures of smartphone use adopted. The main limitation identified in the literature is that the reported associations cannot be given a causal interpretation. Based on the reviewed findings and limitations, directions for further research are discussed.
\end{abstract}

\section{Introduction}

In 2018, approximately 77 percent of America's inhabitants owned a smartphone (Pew Research Center, 2018), defined here as a mobile phone that performs many of the functions of a computer (Alosaimi, Alyahya, Alshahwan, Al Mahyijari, \& Shaik, 2016). In addition, a survey conducted in 2015 showed that 46 percent of Americans reported that they could not live without their smartphone (Smith, 2015). Similar numbers can be observed in other parts of the (Western) world (OECD, 2017). Therefore, it should come as no surprise that in recent years discussions about the (potential) consequences of (heavy) smartphone use have earned an important place in societal debates (see, e.g. Eliahu, 2014; OECD, 2017). Simultaneously, the possible effects of smartphone use received increasing interest from scientists in different disciplines. As such, scholars have investigated associations between smartphone use and smartphone addiction and, for example, (a) driving performance (Choudhary \& Velaga, 2019); (b) sleep quality and quantity (Demirci, Akgönül, \& Akpinar, 2015); (c) anxiety, loneliness, and depression (Boumosleh \& Jaalouk, 2017); (d) satisfaction with life (Samaha \& Hawi, 2016); (e) social relationships (Chen \& Peng, 2008); (f) substance addictions (Ho et al., 2014); and (g) attention deficit and hyperactivity disorder (Ho et al., 2014).

\footnotetext{
*Corresponding author at: Sint-Pietersplein 6, B-9000 Ghent, Belgium.

E-mail addresses: Simon.Amez@UGent.be (S. Amez), Stijn.Baert@UGent.be (S. Baert).
} 
In addition to the (potential) impact on people's private life, smartphone use is also expected to interfere with individuals' educational and professional life. In particular, it has been related to tertiary students' academic performance. Smartphone ownership is highest among people aged 18-29 (Pew Research Center, 2018), an age group in which students are highly represented. Moreover, there are many theoretical reasons based on which a direct effect of (heavy) smartphone use on academic performance is expected. To the best of our knowledge, 23 studies confront the theoretical expectations with the empirical reality. The present review is the first to compile the existing literature on the impact of general smartphone use (and addiction) on performance in tertiary education. ${ }^{1}$

We believe that a synthesis of this literature is valuable to both academics and policy makers. Firstly, as we focus on divergences in the empirical findings-ergo, aspects in which there is no consensus in the literature-and (methodological) limitations of existing studies, we explicitly provide scholars with directions for fruitful future research. Secondly, while in several countries interventions have been developed to discourage heavy smartphone use in class because it is believed to obstruct knowledge acquisition (e.g. in France, a smartphone ban was introduced into schools in 2017; Samuel, 2017), it is unclear whether these popular perceptions correspond with a consensus in the related scientific literature.

This literature review is structured as follows. In the next section, we discuss the different theoretical mechanisms reported in the literature that could lead to improved or deteriorated educational outcomes due to (heavy) smartphone use. In Section 3, we discuss a systematic overview of the empirical findings, with a focus on how the empirical research results converge concerning the overall negative association between smartphone use and academic performance but diverge according to (a) the method of data gathering, (b) the measures of academic performance used in these studies, and (c) the measures of smartphone use adopted in the research. A final section concludes with directions for future research based on the discussed findings and the limitations of the current literature.

\section{Theoretical mechanisms}

Multiple arguments in the existing literature argue for an association-positive or negative-between smartphone use and academic performance. In this section, we review the main theoretical mechanisms.

On the one hand, (particular functions of) smartphones could-when used properly-lead to better educational performance. Smartphones' mobility allows students to access the same (internet-based) services as a computer almost anywhere, almost every time (Lepp, Barkley, \& Karpinski, 2014). Easy accessibility to these functionalities offers students the chance to search continuously for study-related information. Thus, smartphones provide a multi-media platform to facilitate learning which cannot be replaced by reading a textbook (Zhang, Ho, \& Ho, 2014). Furthermore, social networking sites and communication applications may contribute to the quick sharing of relevant information. Faster communication between students and between students and faculty staff may contribute to more efficient studying and collaboration (Chen \& Ji, 2015; Lepp, Barkley, \& Karpinski, 2015).

On the other hand, research has suggested that university students think of their smartphones as a source of entertainment, rather than as a working instrument (Lepp, Barkley, Sanders, Rebold, \& Gates, 2013). These findings support the idea of a time trade-off à la Becker (1965) between smartphone use and study-related activities. That is, the time spent on smartphone use is time lost for study activities. As such, university students' decision to use their smartphones could have a deleterious effect on their academic performance.

Furthermore, smartphone use may interfere with study-related activities. The proximity of the mobile device can be a tempting distraction, leading to multitasking or task-switching. A growing body of literature (see, e.g. Junco, 2012; Junco \& Cotten, 2012; Levine, Waite, \& Bowman, 2012) has shown this behaviour's negative implications with respect to educational performance. We discuss four potential causes for this multitasking or task-switching behaviour. Firstly, visual and auditory notifications on the smartphone may draw students' attention during class and/or during study time (Junco \& Cotten, 2012). Secondly, the desire not to miss out on what is happening online and to continuously interact with the rest of the world (nowadays labelled as 'FOMO', i.e. fear of missing out) may lead to a lack of focus necessary to achieve good study performance (Chen \& Yan, 2016; Firat, 2013). Thirdly, but related, smartphone use during study-related activities may be the result of addiction behaviour and cyberslacking, which can be defined as the interference of personal (online) life during working or study activities (Garrett \& Danziger, 2008; Vitak, Crouse, \& LaRose, 2011). Finally, due to the lack of academic motivation, students can experience a sense of boredom for which smartphone applications provide a fast and tempting escape (Hawi \& Samaha, 2016).

Besides the direct effect smartphone use might have on both time spent and productivity for academic-related activities, smartphone use can have an additional indirect impact on educational performance by influencing students' health. In recent years, an increasing amount of literature provides evidence for a negative relation between technology use, including smartphone use, and health indicators. As such, negative associations were uncovered between smartphone use and (a) sleep quality (Christensen et al., 2016; Demirci et al., 2015; Rosen, Carrier, Miller, Rokkum, \& Ruiz, 2016; Tavernier \& Willoughby, 2014), (b) mental health (Lepp et al., 2014), and (c) physical fitness (Jackson, von Eye, Fitzgerald, Witt, \& Zhao, 2011). These health indicators have in turn been

\footnotetext{
${ }^{1}$ We concentrate on the interference of smartphone use and performance in tertiary education and, thereby, ignore the corresponding literature based on data for secondary education for two different reasons. Firstly, this strategy implies that the reviewed studies are conducted in comparable settings. Typically, differences between the organisation and regulation of secondary education institutions across and within countries exist (see e.g. Beland \& Murphy, 2016 and Gao, Yan, Zhao, Pan and Mo (2014)). Therefore, many institutional modalities should have been considered in our discussion when also focussing on secondary education. Secondly, the body of research on the association between smartphone use and educational outcomes in tertiary education is more substantial than the literature on the same association in secondary education so that a literature review focussing on tertiary education is more appropriate than one focussing on secondary education.
} 
associated with educational performance (see, e.g. Baert, Verhaest, Vermeir, \& Omey, 2015; Galambos, Vargas Lascano, Howard, \& Maggs, 2013).

Taken together, the aforementioned arguments suggest good reasons to expect an association between university students' smartphone use and their academic performance. Smartphones can be supportive in the academic setting by providing easy and fast communication and to search for relevant information. However, the potential negative influence of smartphones through distraction, multitasking, and/or health implications are dominantly advanced in the literature to date.

\section{Empirical findings}

In this section, we summarise the literature's empirical findings on the association between general smartphone use and tertiary educational outcomes. This review is the result of a systematic search. In the first step, all 490 article abstracts indexed in Web of Science including a combination of 'smartphone use' with 'educational outcome' or 'academic performance' were screened for relevance, which provided an initial list of studies for our review. In the second step, we explored (a) the articles included in the studies' references and (b) the articles citing these studies in Web of Science. This second step was re-iterated whenever an additional relevant article was found.

Studies that examine the association between the use of specific smartphone applications and study performance, such as Jacobsen and Forste (2011) and Bun Lee (2014), were excluded. This choice was made to realise a homogeneous literature to review. Moreover, studies investigating the association between the use of particular applications and academic performance ignore the fact that the use of an electronic device for this particular application is strongly correlated with its use for other activities (Chen \& Yan, 2016), potentially resulting in an omitted variable bias.

A schematic overview of the studies can be found in Table 1. The reviewed articles are ordered alphabetically based on the authors' names in column (1). Column (2) contains information on the authors' data: we provide details on how and where the data were gathered and the sample size is reported. Columns (3) and (4) list the variables used in the reviewed studies to capture academic performance and smartphone use, respectively. Finally, column (6) reports the main findings concerning the association between the variables in columns (3) and (4), based on the empirical approach listed in column (5).

\subsection{Main findings}

A quick look at Table 1 reveals the predominance of studies reporting a significantly negative association between smartphone use and academic performance in tertiary education. More specifically, 18 of the 23 included studies (i.e. 78.3 percent), relying on diverging empirical approaches elaborated upon below, conclude such a negative association. The remaining five articles find no statistically significant association between overall smartphone use and performance at university. However, no single study to date reports a positive overall association. ${ }^{2}$ This first look at the literature provides an indication ${ }^{3}$ that the negative mechanisms, as discussed in the previous section, contribute more to the association between smartphone use and academic outcomes than the positive mechanisms.

In column (6) of Table 1, we report significant Pearson correlation coefficients with respect to the studies' measures of these outcomes-they could be gathered for 18 of the 23 studies $^{4}$. These correlation coefficients do not take into account any confounding variables and therefore are not the analysis end point in most reviewed articles. However, they allow us to compare a raw indicator of the magnitude of the association between smartphone use and academic performance across studies. The reported coefficients range from a correlation coefficient of -0.380 between total phone use in class and self-reported grade point average (GPA) in Kim et al. (2019) to a correlation coefficient of 0.047 between the problematic mobile phone use scale of Sert, Yilmaz, Kumsar and Aygin (2019) and self-reported GPA. When considering only correlation coefficients of studies that concluded a statistically significantly negative association, not surprisingly the interval is less wide. Then it moves from a very small correlation of -0.079 (Lin \& Chiang, 2017) to a (rather) small correlation of -0.380 (Kim et al., 2019) In sum, the reviewed literature seems to suggest a negative association between overall smartphone use and academic performance that is small in magnitude (at most). However, this general picture may conceal interesting (further) convergences and divergences in the literature that can be observed only after investigating the studies more carefully, which is addressed in the next two subsections.

\subsection{Convergences in the empirical literature}

The statistical and economic magnitude of the association between smartphone use and academic performance seems to be rather homogeneous by (a) the public versus private nature of tertiary education institutions, (b) the method of data analysis as well as by (c) the region and sample size of the realised data.

Firstly, one could expect that the students in samples from private universities are positively selective with respect to non-

\footnotetext{
${ }^{2}$ Chen and Peng (2008) report a positive association in the particular situation when personal electronic devices are (mainly) used for educational purposes.

${ }^{3}$ The reported associations cannot be given a causal interpretation, though. We return to this point below.

${ }^{4}$ The Pearson correlation coefficient was reported in 15 of the articles. For the other articles, we attempted to obtain this coefficient from the authors via email, or, when our email was not answered, via telephone (using both personal and institution numbers).
} 


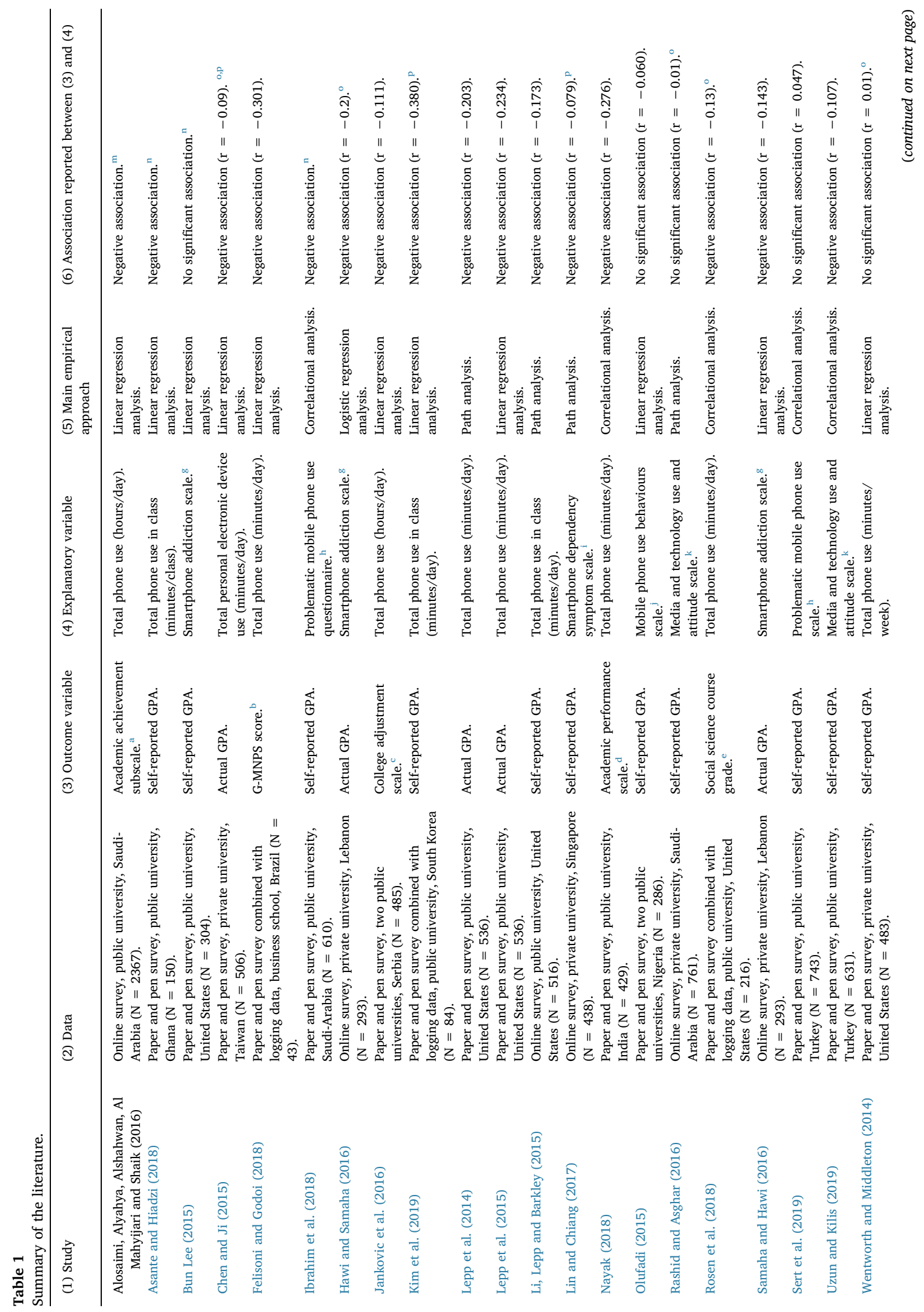




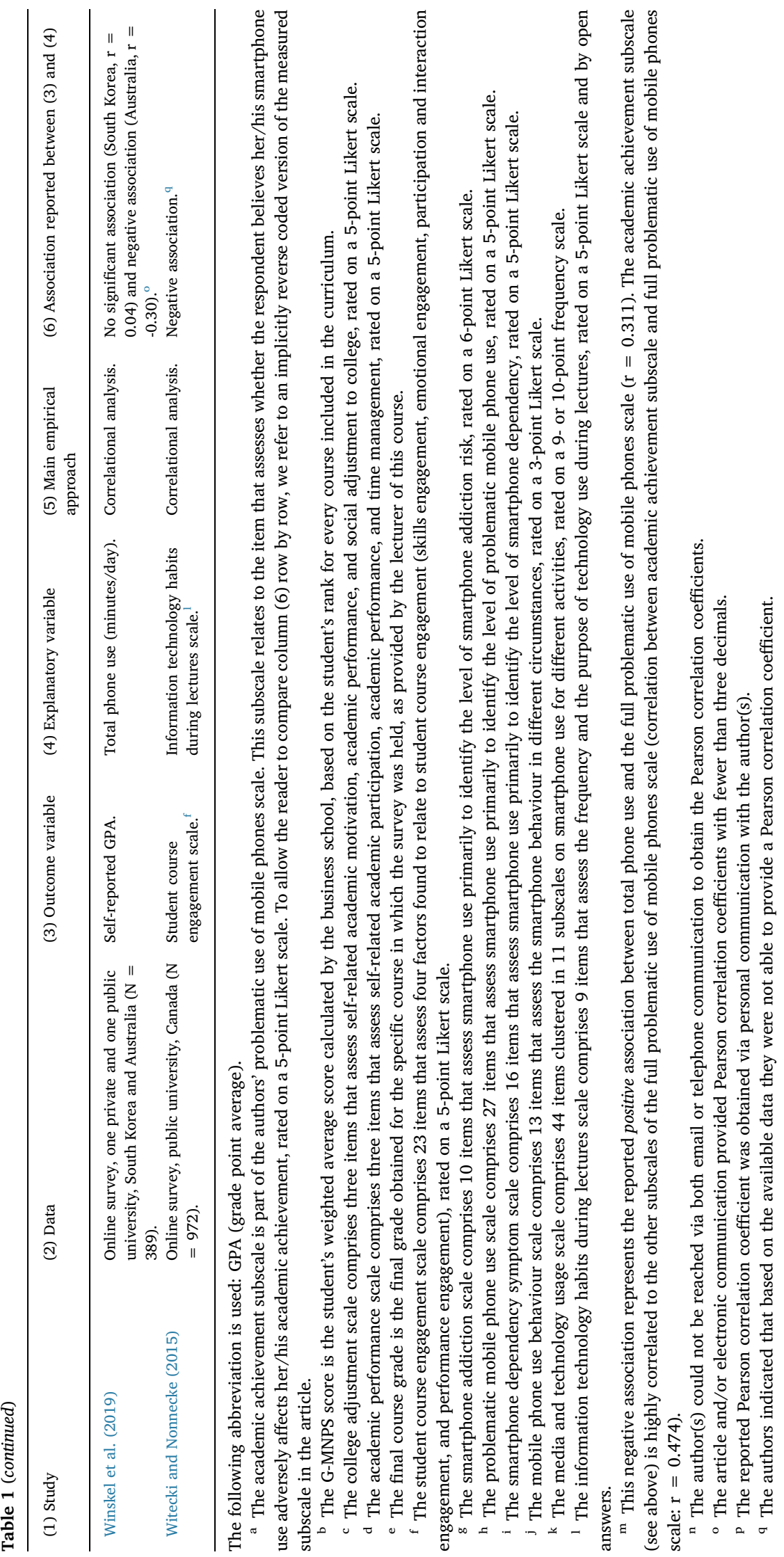


observed characteristics like internal motivation and ability (Di Pietro \& Cutillo, 2006; James, 1994; Ladd, 2002). For these students, several of the theoretical mechanisms supporting a negative association between smartphone use and academic performance might be less relevant. In 15 cases, the research population was matriculated at a publicly funded university at the time of the research. Twelve of them report a significantly negative association. In seven studies, the research was conducted at a private university or a business school. Five of these studies report a significantly negative association. Winskel, Kim, Kardash and Belic (2019) studied students from both private and publicly funded institutions but only find a negative significant association for the subsample of students matriculated at a publicly funded institution. Thus, the empirical evidence to date suggest a negative association between smartphone use and academic performance, regardless of the public or private nature of the education institution.

The association between smartphone use and academic performance has been investigated on all continents. However, most studies were conducted in North America and Asia. No remarkable differences were noticed between the studies relying on data from these two continents. Among the North American studies, Bun Lee (2015) and Wentworth and Middleton (2014) found no significant association while a negative association was concluded in the five other articles. Similarly, two of the Asian-based investigations (Rashid \& Asghar, 2016; Sert et al., 2019) did not report a significant association while a negative association was reported by the nine other studies. Furthermore, Winskel et al. (2019) found no significant association for their Korean subsample. For their Australian (Oceania) they reported a significantly negative association. Besides, Felisoni and Godoi (2018) and Jankovic, Nikolic, Vukonjanski and Terek (2016) reported a significantly negative association in Brazil (South America) and Serbia (Europe), respectively. Finally, among the studies relying on African data, Olufadi (2015) found no significant association in Nigeria while Asante and Hiadzi (2018) reported a negative association in Ghana.

Except for Jankovic et al. (2016), Nayak (2018), and Winskel et al. (2019), all studies were based on surveys with students from one single educational institution. However, the sample sizes range from 43 to 2367 participants. Therefore, it could be postulated that the reported non-significant associations in Table 1 are due to a lack of statistical power in the smaller samples. Of the eleven articles with a sample size lower than the median ( $=483)$, only Olufadi (2015) and Bun Lee (2015) did not report a significant association. Likewise, two studies (Rashid \& Asghar, 2016; Sert et al., 2019) with a sample size higher than the median sample size found no significant association. Finally, Wentworth and Middleton (2014), whose sample size (N = 483) coincides with the median sample size, reported no significant association between smartphone use and academic performance. In sum, the insignificant associations reported in the literature do not appear to be driven by (studies with) smaller sample sizes.

Finally, the research results are rather homogeneous according to the level of control for confounding factors in the main empirical approach. Importantly, none of the empirical results summarised in Table 1 can be given a causal interpretation; that is, to date there is only evidence for heavy smartphone users performing worse at higher education institutions, with no support for heavy smartphone use causing this worse performance. None of the approaches mentioned in column (5) of Table 1 can fully control for the endogeneity of smartphone use and academic achievement because they all rely on observational, cross-sectional data. Thus, they can only control for a limited set of confounders. However, factors such as motivation, intellectual capabilities and perceived academic pressure are typically not included in their collected survey data but might influence both smartphone use and academic performance. Thereby, it is unclear whether the worse performance of heavy smartphone users reported by many of these studies is really the result of smartphone use or reflects variation in unobserved personal characteristics.

Nevertheless, the studies included in Table 1 differ in the extent to which they attempt to control for confounding variables. In this respect, the negative association between smartphone use and academic performance is not more or less outspoken when such controls are taken into account in a regression analysis. Among the nine reviewed articles that only calculate correlation coefficients, only Olufadi (2015) and Sert et al. (2019) did not find a significant association. The remaining 14 articles perform at least one form of regression analysis. Nine of them perform a linear regression analysis, four conduct a path analysis and one opts for a logistic regression as main approach. Eleven times the regression coefficient with respect to the association between overall smartphone use and academic performance is significantly negative.

\subsection{Divergences in the empirical literature}

By contrast, the association between smartphone use and academic performance seems to be heterogeneous by (a) the method of data gathering, (b) the measures of academic performance used in the analysis, and (c) the measures of smartphone use adopted in the research.

Firstly, all studies in Table 1 are (mainly) based on survey data: Seven rely on an online survey and another 12 rely on a paper and pencil survey. Winskel et al. (2019) rely partly on an online survey for the Korean subsample and partly on a paper and pencil survey for their Australian subsample. In addition, Felisoni and Godoi (2018), Rosen et al. (2018), and Kim et al. (2019) combined a paper and pencil survey with objective logged data, which is a strong point for these studies as Boase and Ling (2013) reported a limited correlation between self-reported smartphone use and actual logged data-we return to this point below. Four of the five studies reporting no significant association between smartphone use and academic performance are relying on data gathered by a paper and pencil questionnaire. A possible explanation might be that those questionnaires are filled in during a course and therefore participants are surrounded by peers which might increase the tendency to social desirable answers (Krumpal, 2013).

Secondly, across the reviewed studies, three measures of academic performance are used. Six studies use data on students' actual grades received from the lecturer or from the faculty or university administration. All of these studies conclude a significantly negative association between smartphone use and these outcomes. In addition, 11 studies rely on self-reported grades. Remarkably, all five articles not reporting a negative association fall within these 11 studies. Finally, The six studies using self-reported academic performance scales all found a negative association. This contrast may indicate that errors of measurement occurred in the self- 
reported grade variables. Indeed, these variables may be biased due to recall issues or socially desirable answering (Krumpal, 2013 ). ${ }^{5}$

Thirdly, we distinguish a similar difference in research results depending on how smartphone use is measured. In 12 articles, the researchers investigate the association between academic performance and total smartphone use. Except for Felisoni and Godoi (2018), Rosen et al. (2018), and Winskel et al. (2019), who used objectively tracked information, these frequencies are self-reported. Of these twelve studies, only Wentworth and Middleton (2014) did not report a significant association while Winskel et al. (2019) find a significant negative association for their Australian subsample and no significant association for the Korean subsample. In contrast, of the other 11 studies, using a scale instrument to measure smartphone attitude and addiction, only seven find a significantly negative association. In line with our explanation for the former two divergences in the literature, it might be the case that students tend more to social desirable answers (Krumpal, 2013) when inquired about attitude or addiction compared to frequency of phone use.

\section{Conclusion}

In this article, we reviewed the scientific literature to date on the relationship between smartphone use and academic performance in tertiary education. Our analysis of the literature reveals a predominance of empirical results supporting a negative association. However, this predominance is less outspoken in studies analysing data gathered by paper and pen questionnaires (compared with studies on data gathered by online surveys) and studies relying on self-reported grade point averages (compared with studies using actual grades). In general, when scholars use methods of data gathering which are more susceptible to social desirable behaviour, a non-significant association is found more often.

The main limitation identified in the literature is that the existing studies all conduct correlational analyses and/or linear or logistic regression analyses on cross-sectional data so that their results cannot be given a causal interpretation. We suggest two different forms of analysis to counter this endogeneity problem that could be explored in further research. Firstly, longitudinal data could be collected in view of regression analyses controlling for individual fixed effects. By integrating fixed effects into the analysis, it is possible to control for time-invariant unobserved characteristics of university students that may affect both smartphone use and academic performance. Secondly, instrumental variables correlated with smartphone use but not (directly) affecting educational attainment (such as perceived quality of the WiFi network in the classrooms) may be surveyed. These can be used to capture an exogenous prediction of smartphone use. Thereafter, the causal impact on academic performance of this exogenous prediction can be estimated.

A second limitation of the literature is related to the analysed data. As pointed out in the empirical findings section, 20 out of 23 reviewed articles used self-reported measures of smartphone use in their analysis. Felisoni and Godoi (2018), Rosen et al. (2018), and Kim et al. (2019) made a first attempt to introduce actual tracked use in their analysis but they had a rather small sample size $(\mathrm{N}=$ 43, 216, and 84 respectively). However, Boase and Ling (2013) provided evidence for only a limited correlation between actual smartphone use and that measured by self-reported instruments. So, it is recommended for future research to further investigate whether the results based on self-reported measures can be confirmed when analysing actual data.

A third shortcoming in the scientific literature so far is the lack of research investigating the empirical validity of the reviewed theoretical mechanisms for a potential impact of smartphone use on academic performance. However, uncovering the mechanisms at work is of great importance for policy making. To implement adequate policy measures on smartphone use in academic settings, we need to know what precisely causes their (potential) relationship. Tracking university students' smartphone use, as advocated above, may also help in this respect. Actual tracked data would provide more insight into the timing of students' smartphone use. This could reveal indications for the multitasking mechanism and/or the time trade-off argument behind the association between smartphone use and academic performance.

\section{Appendix A. Supplementary data}

Supplementary material related to this article can be found, in the online version, at doi:https://doi.org/10.1016/j.ijer.2020. 101618.

\section{References}

Alosaimi, F. D., Alyahya, H., Alshahwan, H., Al Mahyijari, N., \& Shaik, S. A. (2016). Smartphone addiction among university students in Riyadh, Saudi Arabia. Saudi Medical Journal, 37, 675-683.

Asante, R. K. B., \& Hiadzi, R. A. (2018). In-lecture smartphone use and academic performance: A reflection on the sustainable development goal number four. Ghana Social Science Journal, 15, 161-178.

Baert, S., Verhaest, D., Vermeir, A., \& Omey, E. (2015). Mister sandman, bring me good marks! On the relationship between sleep quality and academic achievement. Social Science \& Medicine, 130, 91-98.

Becker, G. S. (1965). A theory of the allocation of time. The Economic Journal, 75, 493-517.

Beland, L. P., \& Murphy, R. (2016). III Communication: Technology, distraction \& student performance. Labour Economics, 41, 61-76.

Boase, J. A., \& Ling, R. (2013). Measuring mobile phone use: Self-report versus log data. Journal of Computer Mediated Communication, $18,508-519$.

Boumosleh, J. M., \& Jaalouk, D. (2017). Depression, anxiety and smartphone addiction in university students—A cross sectional study. PloS One, 12 , e0182239.

Bun Lee, E. (2014). Facebook use and texting among African American and Hispanic teenagers: An implication for academic performance. Journal of Black Studies, 45, 83-101.

\footnotetext{
${ }^{5}$ In this respect, survey questions directly assessing GPA may be more sensitive than items from the broader achievement, adjustment, or engagement scales listed in Table 1.
} 
Bun Lee, E. (2015). Too much information: Heavy smartphone and Facebook utilization by African American young adults. Journal of Black Studies, 46, 44-61.

Chen, R. S., \& Ji, C. H. (2015). Investigating the relationship between thinking style and personal electronic device use and its implications for academic performance. Computers in Human Behavior, 52, 177-183.

Chen, Y. F., \& Peng, S. S. (2008). University students' internet use and its relationships with academic performance, interpersonal relationships, psychosocial adjustment and selfevaluation. CyberPsychology \& Behavior, 11, 467-469.

Chen, Q., \& Yan, Z. (2016). Does multitasking with mobile phones affect learning? A review. Computers in Human Behavior, 54, 34-42.

Choudhary, P., \& Velaga, N. R. (2019). Effects of phone use on driving performance: A comparative analysis of young and professional drivers. Safety Science, 111 , $179-187$.

Christensen, M. A., Bettencourt, L., Kaye, L., Moturu, S. T., Nguyen, K. T., Olgin, J. E., et al. (2016). Direct measurements of smartphone screen-time: Relationships with demographics and sleep. PloS One, 11, e0165331.

Demirci, K., Akgönül, M., \& Akpinar, A. (2015). Relationship of smartphone use severity with sleep quality, depression, and anxiety in university students. Journal of Behavioral Addictions, 4, 85-92.

Di Pietro, G., \& Cutillo, A. (2006). University quality and labour market outcomes in Italy. Labour, 20, 37-62.

Eliahu, J. (2014). 10 ways smartphones have completely ruined our lives. Retrieved from https://thoughtcatlog.com/jim-eliahu/2014/04/10-ways-smartphones-have-completelyruined-our-lives on 22 October 2019.

Felisoni, D. D., \& Godoi, A. S. (2018). Cell phone usage and academic performance: An experiment. Computers \& Education, 117, $175-187$.

Firat, M. (2013). Multitasking or continuous partial attention: A critical bottleneck for digital natives. Turkish Online Journal of Distance Education, $14,1302-6488$.

Galambos, N. L., Vargas Lascano, D. I., Howard, A. L., \& Maggs, J. L. (2013). Who sleeps best? Longitudinal patterns and covariates of change in sleep quantity, quality, and timing across four university years. Behavioral Sleep Medicine, 11, 8-22.

Gao, Q., Yan, Z., Zhao, C., Pan, Y., \& Mo, L. (2014). To ban or not to ban: Differences in mobile phone policies at elementary, middle, and high schools. Computers in Human Behavior, 38, 25-32.

Garrett, R. K., \& Danziger, J. N. (2008). On cyberslacking: Workplace status and personal internet use at work. CyberPsychology \& Behavior, 11, 287-292.

Hawi, N. S., \& Samaha, M. (2016). To excel or not to excel: Strong evidence on the adverse effect of smartphone addiction on academic performance. Computers \& Education, 98, $81-89$.

Ho, R. C., Zhang, M. W. B., Tsang, T. Y., Toh, A. H., Pan, F., Lu, Y., et al. (2014). The association between internet addiction and psychiatric co-morbidity: A meta-analysis. BMC Psychiatry, 14, 183.

Ibrahim, N. K., Baharoon, B. S., Banjar, W. F., Jar, A. A., Ashor, R. M., Aman, A. A., et al. (2018). Mobile phone addiction and its relationship to sleep quality and academic achievement of medical students at King Abdulaziz University, Jeddah, Saudi Arabia. Journal of Research in Health Sciences, 18 , e00420.

Jackson, L. A., von Eye, A., Fitzgerald, H. E., Witt, E. A., \& Zhao, Y. (2011). Internet use, videogame playing and cell phone use as predictors of children's body mass index (BMI), body weight, academic performance and social and overall self-esteem. Computers in Human Behavior, 27, 599-604.

Jacobsen, W. C., \& Forste, R. (2011). The wired generation: Academic and social outcomes of electronic media use among university students. Cyberpsychology, Behavior and Social Networking, 14, 275-280.

James, E. (1994). The public-private division of responsibility for education. International Journal of Educational Research, 21, 777-783.

Jankovic, B., Nikolic, M., Vukonjanski, J., \& Terek, E. (2016). The impact of Facebook and smartphone usage on the leisure activities and college adjustment of students in Serbia. Computers in Human Behavior, 55, 354-363.

Junco, R. (2012). In-class multitasking and academic performance. Computers in Human Behavior, 28, 2236-2243.

Junco, R., \& Cotten, S. R. (2012). Not A 4 U: The relationship between multitasking and academic performance. Computers \& Education, 59, 505-514.

Kim, I., Kim, R., Kim, H., Kim, D., Han, K., Lee, P. H., et al. (2019). Understanding smartphone usage in college classrooms: A long-term measurement study. Computers \& Education, 141, 103611.

Krumpal, I. (2013). Determinants of social desirability bias in sensitive surveys: A literature review. Quality \& Quantity, 47, $2025-2047$.

Ladd, H. F. (2002). School vouchers: A critical view. The Journal of Economic Perspectives, 16, 3-24.

Lepp, A., Barkley, J. E., \& Karpinski, A. C. (2014). The relationship between cell phone use, academic performance, anxiety, and satisfaction with life in college students. Computers in Human Behavior, 31, 343-350.

Lepp, A., Barkley, J. E., \& Karpinski, A. C. (2015). The relationship between cell phone use and academic performance in a sample of U.S. college students. SAGE Open, 5, 2158244015573169.

Lepp, A., Barkley, J. E., Sanders, G. J., Rebold, M., \& Gates, P. (2013). The relationship between cell phone use, physical and sedentary activity, and cardiorespiratory fitness in a sample of U.S. college students. The International Journal of Behavioral Nutrition and Physical Activity, 10, 79.

Levine, L. E., Waite, B. M., \& Bowman, L. L. (2012). Mobile media use, multitasking and distractibility. International Journal of Cyber Behavior Psychology and Learning, 2, 15-29.

Li, J., Lepp, A., \& Barkley, J. E. (2015). Locus of control and cell phone use: Implications for sleep quality, academic performance and subjective well-being. Computers in Human Behavior, 52, 450-457.

Lin, T. T. C., \& Chiang, Y. H. (2017). Investigating predictors of smartphone dependency symptoms and effects on academic performance, improper phone use and perceived sociability. International Journal of Mobile Communications, 15, 655-676.

Nayak, J. K. (2018). Relationship among smartphone usage, addiction, academic performance and the moderating role of gender: A study of higher education students in India. Computers \& Education, 123, 164-173.

OECD (2017). OECD digital economy outlook 2017. Paris: OECD.

Olufadi, Y. (2015). A configurational approach to the investigation of the multiple paths to success of students through mobile phone use behaviors. Computers \& Education, 86, 84-104.

Pew Research Center (2018). Mobile fact sheet. Retrieved from http://www.pewinternet.org/fact-sheet/mobile/ on 22 October 2019.

Rashid, T., \& Asghar, H. M. (2016). Technology use, self-directed learning, student engagement and academic performance: Examining the relations. Computers in Human Behavior, 63, 604-612.

Rosen, L. D., Carrier, L. M., Pedroza, J. A., Elias, S., O’Brien, K. M., Lozano, J., et al. (2018). The role of executive functioning and technological anxiety (FOMO) in college course performance as mediated by technology usage and multitasking habits. Psicologia Educativa, 24, 14-25.

Rosen, L. D., Carrier, L. M., Miller, A., Rokkum, J., \& Ruiz, A. (2016). Sleeping with technology: Cognitive, affective, and technology usage predictors of sleep problems among college students. Sleep Health, 2, 49-56.

Samaha, M., \& Hawi, N. S. (2016). Relationships among smartphone addiction, stress, academic performance and satisfaction with life. Computers in Human Behavior, 57, $321-325$.

Samuel, H. (2017). France to impose total ban on mobile phones in schools. Retrieved from http://www.telegraph.co.uk/news/2017/12/11/france-impose-total-ban-mobile-phonesschools/ on 22 October 2019.

Sert, H., Yilmaz, F. T., Kumsar, A. K., \& Aygin, D. (2019). Effect of technology addiction on academic success and fatigue among Turkish university students. Fatigue Biomedicine Health \& Behavior, 7, 41-51.

Smith (2015). US smartphone use in 2015. Pew Research Center Retrieved from http://www.pewinternet.org/files/2015/03/PI_Smartphones_0401151.pdf on 22 October 2019.

Tavernier, R., \& Willoughby, T. (2014). Sleep problems: Predictor or outcome of media use among emerging adults at university? Journal of Sleep Research, 23, 389-396.

Uzun, A. M., \& Kilis, S. (2019). Does persistent involvement in media and technology lead to lower academic performance? Evaluating media and technology use in relation to multitasking, self-regulation and academic performance. Computers in Human Behavior, 90, 196-203.

Vitak, J., Crouse, J., \& LaRose, R. (2011). Personal Internet use at work: Understanding cyberslacking. Computers in Human Behavior, $27,1751-1759$.

Wentworth, D. K., \& Middleton, J. H. (2014). Technology use and academic performance. Computers \& Education, 78, 306-311.

Winskel, H., Kim, T. H., Kardash, L., \& Belic, I. (2019). Smartphone use and study behavior: A Korean and Australian comparison. Heliyon, 5 , e02158.

Witecki, G., \& Nonnecke, B. (2015). Engagement in digital lecture halls: A study of student course engagement and mobile device use during lecture. Journal of Information Technology Education Research, 14, 73-90.

Zhang, M. W. B., Ho, C. S. H., \& Ho, C. M. (2014). Methodology of development and students' perceptions of a psychiatry educational smartphone application. Technology and Health Care, 22, 847-855. 